\title{
Neighborhood Institutions, Facilities, and Public Space: A Missing Link for HOPE VI Residents' Development of Social Capital?
}

Alexandra M. Curley

OTB Research Institute for Housing, Urban and Mobility Studies

\begin{abstract}
This study assessed the factors that shaped the development of shared trust, norms, reciprocity (TNR), and social ties_-important foundations of social capital-for low-income HOPE VI (Housing Opportunities for People Everywhere) residents who relocated to new communities. A longitudinal mixed-methods approach revealed the distinct but understudied role that neighborhood institutions, facilities, and public spaces play in shaping observations, encounters, and interactions with other coresidents (as well as outsiders). Multivariate analyses of survey data indicate that neighborhood facilities and public spaces, such as parks, libraries, and recreation facilities, were very strong predictors of TNR among neighbors. Indepth interviews with relocated women revealed the ways in which neighborhood structure and public spaces can shape social encounters and relations in the neighborhood. This article presents a discussion of the ways in which these important but often overlooked neighborhood attributes can structure contact with neighbors and considers implications for policies aimed at improving low-income people's access to social capital through relocation.
\end{abstract}

\section{Introduction}

Although the concept of social capital is being used increasingly in policy discourse, our comprehension of how social capital is built, maintained, and accessed is far from complete. This article seeks to further our understanding by examining some of the potential mechanisms for developing 
social capital in the neighborhood and by considering how relocation might shape residents' access to social capital. This study addresses a key question: What is the role of the neighborhood for the development of trust, interactions, and ties with coresidents and with outsiders? Specifically, the study explores how neighborhood attributes affected the development of these important precursors to social capital for low-income residents who were relocated to different types of communities through the HOPE VI Program.

Social capital describes a unique and important set of resources that can both depend on and enhance our economic and human capital (Bourdieu, 1986). As a resource that flows through social networks and relationships based on trust, norms, and reciprocity (TNR), social capital helps facilitate productive activity that can benefit individuals and groups (Coleman, 1988; Putnam, 2000). Much of the social capital literature has focused on social networks and how they can help us "get by" and "get ahead" in life by providing resources of support and social leverage (Briggs, 1998) and on the relative importance of "weak" or "bridging" ties in particular for accessing upward mobility opportunities (Granovetter, 1973; Putnam, 2000). Other social capital research has focused on aggregate levels of trust and civic engagement (Putnam, 2000), or has highlighted the informal social control that can be generated from social capital (Sampson, Raudenbush, and Earls, 1997). Although definitions of social capital are widely debated (see Fulkerson and Thompson, 2008; Portes, 1998; Portes and Landolt, 2000), in this article we define social capital as the actual or potential resources that can be accessed through social relationships where TNR are established. Therefore, social ties and trust are not social capital but, rather, are the prerequisites for social capital.

The latest wave of "neighborhood effects" research has brought social capital and social networks to the forefront of numerous academic and policy discussions as a potential mechanism through which neighborhood disadvantage might be channeled. It has been argued that living in povertyconcentrated neighborhoods, for example, can shape the social capital resources to which one has access (Wilson, 1987). In neighborhoods where most residents are disadvantaged, marginalized, or disconnected from "mainstream" society, residents may have access to a limited set of information and opportunities through their social networks, compared with those who live in economically mixed or higher income neighborhoods. Thus, inadequate access to social capital has been added to a growing list of conditions characteristic of high-poverty neighborhoods (for example, poor housing quality, crime and social disorder, and pervasive joblessness) that put residents at a severe disadvantage for escaping poverty and achieving upward mobility. The idea that neighborhood demographics affect residents' access to social capital has informed urban housing policies that seek to alter the demographic makeup in high-poverty neighborhoods. In countries including the United States, the United Kingdom, Australia, and the Netherlands, creating mixed-income communities has become an explicit policy goal for urban redevelopment initiatives targeting highpoverty neighborhoods, partly due to the assumption that mixed-income environments are richer in trust, shared norms, and resourceful social networks. Mixed-income neighborhoods are thought to provide lower income people with greater opportunities to connect with people who adhere to "mainstream" norms of work and family and to tap into better job networks (Wilson, 1987). 


\section{Research and Literature}

This section reviews a number of empirical and theoretical studies that contribute to the present understanding of how neighborhoods can shape the development of residents' social capital in an effort to understand how HOPE VI relocation might affect low-income residents' access to social capital. This section first provides a brief review of the research on neighborhood population characteristics and social networks. Next, it turns to the literature that explores the role of neighborhood institutions before finally considering the contributions from research on trust, public familiarity, and stigma, which may help further the understanding of social capital development in a neighborhood context.

Wilson's (1987) research suggests that poverty concentration at the neighborhood level can shape residents' social networks by limiting everyday opportunities to interact and form relations with higher income people who have long-term attachments to the workforce. Some studies have proposed that residents in such communities are lacking "weak" or "bridging" ties to working- or middle-class people who have access to important information and resources necessary for upward mobility (Granovetter, 1973; Putnam, 2000). Some evidence indicates that people living in high-poverty communities have social networks that are more homogeneous and dense than the social networks of people living in low-poverty areas, suggesting that information on jobs and other opportunities may be more redundant in high-poverty neighborhoods (Dominguez and Watkins, 2003; Smith, 1995). Poor urban residents were often found to have insular and localized social networks that offered little opportunity for advancement (Tigges, Browne, and Green, 1998; Wacquant and Wilson, 1989; Wilson, 1996, 1987). In his study of low-income Latino and AfricanAmerican youth, Briggs (1998) found that those who had wider and more diverse networks had more access to job information.

While our social worlds today are less likely to be bound by our neighborhoods of residence due to advancements in communication and transportation (Guest and Wierzbicki, 1999; Wellman, 2001), spatial proximity may still influence the development of social ties (Mok, Wellman, and Antonia-Carrasco, 2008; Wellman, 1996), particularly for lower income people who are more bound to a place due to limited resources (as well as those who have limited mobility, including elderly people and people with disabilities). ${ }^{1}$ Length of residence may also have a positive association with neighborhood-based social networks as people become more embedded in their communities and get to know their neighbors over time (Coleman, 1988; Saegert and Winkel, 2004). Others, however, have pointed out that physical proximity to higher income people alone does not automatically translate into having helpful social ties (Curley, 2009), because factors such as social status (Lin and Dumin, 1986), trust, reputation, motivation, community context (Smith, 2005, 2007), pride, shame, and stigma (Blokland and Noordhoff, 2008) can complicate the mobilization

\footnotetext{
${ }^{1}$ Some studies have found that people with more education and higher incomes have larger and more geographically dispersed social networks, partly because they are less constrained by limited resources to travel (Fischer, 1982). Unemployed people, in contrast, tend to have more neighborhood-based social ties, because they depart the neighborhood less regularly (Fischer, 1982). Households with children are thought to have greater social capital because the members of the household typically spend more time in the community and have multiple avenues for connecting with people in the neighborhood (Kleinhans, Priemus, and Engbersen, 2007; Saegert and Winkel, 2004).
} 
of such ties. Further, social proximity may be more important than physical proximity, as people are drawn to others like themselves in terms of lifestyle, social status, and values (that is, "birds of a feather flock together") (McPherson, Smith-Lovin, and Cook, 2001). There is some evidence that ethnic diversity at the neighborhood level may have a negative association with local social relations, because residents in homogeneous communities may be more likely to trust their neighbors and be involved with their communities (Fischer, 1982; Putnam, 2007).

Although many questions remain about the effects of neighborhood poverty concentration on social networks and the relative importance of social versus physical proximity for local social ties, inquiry into what happens to low-income individuals' networks when they relocate out of high-poverty areas is also growing. Attention to this issue was prompted with the development of programs across the United States and Europe designed to relocate poor people in an effort to deconcentrate poverty, create mixed-income neighborhoods, and improve the life chances of the poor. Two such programs in the United States_-HOPE VI and MTO (Moving to Opportunity) have relocated tens of thousands of low-income families from high-poverty communities in the past decade. By decreasing poverty concentration through relocation or redevelopment, it is assumed that lower income residents will be more exposed to higher income people and might diversify their social networks to include them. Few studies have provided evidence, however, that mixedincome programs (or relocation initiatives) improve low-income residents' access to social capital. In fact, studies on both sides of the Atlantic show little social mixing among higher and lower income people in redeveloped mixed communities (Brophy and Smith, 1997; Buron et al., 2002; Curley, 2009; Kleinhans, 2004; Smith, 2002; van Beckhoven and van Kempen, 2003), suggesting that increased residential proximity does not necessarily promote social interaction. Others have similarly found that low-income movers tend not to receive job information from their new neighbors, challenging the assumption that higher income neighbors will become useful or willing job contacts or that altering neighborhood demographic composition will promote the development of social capital (Briggs et al., 2007; Curley, 2009; Kleit, 2001). ${ }^{2}$

In addition to the potential effect neighborhood population demographics may have on the development of trust and relations among neighbors, other neighborhood attributes may play a role as well, including physical structure of the neighborhood, its institutions and public spaces, and even neighborhood stigma. Although few studies have explored the explicit link between local institutions or other neighborhood features and social capital development in the context of a relocation program, a number of studies have suggested that neighborhood institutions are important for community stability, social control, collective efficacy, and social democracy. These studies are informative because they highlight the important role of local institutions and public spaces and provide a framework for understanding how neighborhoods may shape HOPE VI relocatees' development of trust and social relations in their communities.

\footnotetext{
${ }^{2}$ Although one study assessing the MTO program found that moving to a low-poverty neighborhood increased the chances that adults would have friends who graduated from college or earned more than $\$ 30,000$ a year, only 8 percent of participants in the study found a job through a neighborhood tie, and no differences existed between those in high- and low-poverty neighborhoods (Kling, Liebman, and Katz, 2005; Orr et al., 2003). Further, HOPE VI researchers found that relocation often broke up strong social networks, which could reduce access to social support—another important form of social capital (Clampet-Lundquist, 2004; Curley, 2009; Greenbaum, 2002; Popkin, Levy et al., 2004; Saegert and Winkel, 1998).
} 
For example, in The Truly Disadvantaged, Wilson (1987) emphasized the role local social institutions played in maintaining stability in urban neighborhoods. He argued that one consequence of the outmigration of the African American working and middle classes from American cities in the 1970s was the removal of an institutional base and the stability and social control it brought to those neighborhoods. As families from those urban neighborhoods left for the suburbs, so too did the businesses and services (for example, grocery stores, churches, banks, and restaurants) that catered to and were supported by them. The resulting lack of institutional stability compounded with the increasing concentration of economic deprivation created socially isolated communities with few resources to leverage political and economic investment. ${ }^{3}$ Sánchez-Jankowski's (2008) ethnographic research similarly highlighted the ways in which local institutions such as beauty salons and "mom and pop" stores can play an important socialization function in poor neighborhoods and contribute to a sense of community, stability, and social order. Peterson, Krivo, and Harris (2000) also pointed to the importance of institutions: "When local organizations that link individuals to each other and to broader political and economic institutions are less prevalent, commitments to mainstream values are less likely to be encouraged, socialization to conformity is undermined, and the resulting indirect social control is weakened" (Peterson, Krivo, and Harris, 2000: 34). In multivariate analyses of census and crime data, they found that the presence of recreation centers reduced violent crime in areas with extreme economic deprivation, suggesting that such facilities and their programs may serve an important social control function (Peterson, Krivo, and Harris, 2000). Neighborhood institutions may promote mechanisms of informal social control by providing a venue for social interaction and for developing collective efficacy (Sampson, Raudenbush, and Earls, 1997), which has been defined as the trust, shared expectations, and willingness to intervene in one's community. ${ }^{4}$ Related to these mechanisms of social control is the ability of residents to realize their common values and goals. In Bowling Alone, Putnam (2000) raised alarm about the declining civic engagement of Americans and the implications of a weakened institutional base. He argued that declining participation in formal membership-based organizations, religious institutions, and politics (voting) was indicative of a broader trend of declining social capital, which he contended threatens the democratic and social fabric of our society.

While the previously discussed quantitative and qualitative studies highlight the important links between institutions and neighborhood stability, social control, and trust, only two known quantitative studies have documented a clear connection between neighborhood facilities and local social networks. These studies include those of Van Bergeijk, Bolt, and van Kempen (2008), who found

\footnotetext{
${ }^{3}$ Interestingly, however, Small and McDermott (2006) found that neighborhood poverty level had a positive relationship with the number of organizational resources in the neighborhood (such as grocery stores, pharmacies, and childcare centers). In another study, Small, Jacobs, and Massengill (2008) examined the interorganizational ties of childcare centers in New York and found that centers in high-poverty neighborhoods were better connected and had more referral and organizational ties, challenging the general belief that concentrated poverty weakens the capacity for strong, local organizations. Small's (2006) research also suggests that as "resource brokers" and as sites for social interaction, neighborhood institutions and their connections may play an important mediating role between neighborhood poverty and well-being.

${ }^{4}$ In their analyses of resource inequality, social processes, and spatial dynamics that might predict rates of homicide, Morenoff, Sampson, and Raudenbush (2001) found that, although the number of local organizations alone was "relatively unimportant" (Morenoff, Sampson, and Raudenbush, 2001: 553), local organizations and social networks were valuable for their ability to "promote the collective efficacy of residents in achieving social control and cohesion" (Morenoff, Sampson, and Raudenbush, 2001: 517).
} 
that use of neighborhood facilities had a positive effect on social networks in distressed neighborhoods undergoing renewal in the Netherlands, and Dekker and Filipovic (2008), who found that residents of large housing estates in the Netherlands and Slovenia who reported problems with the upkeep of public space and local services had fewer social ties in the neighborhood and were less positive about social contacts in the neighborhood compared with those who were satisfied with public spaces and services.

Although most of the previously discussed studies highlight the importance of neighborhood institutions for the stability they bring to communities, research on trust and public familiarity suggests that local institutions and public spaces might play another important role. A small number of qualitative studies, although not necessarily making connections to social capital, provide insight in how trust, public familiarity, and social relations can develop in the public domain. By studying social order in "a world of strangers," Lofland (1973) found that when "conventional encounters occurred repeatedly in a single public locale, they become... one of the mechanisms by which total strangers are transformed into personally-known others" (Lofland, 1973: 168). In other words, when we come across the same people repeatedly in public spaces, we can develop a sense of "public familiarity." "Public familiarity arises when interdependent anonymous people keep encountering each other..." (Blokland, 2003: 93). In his empirical research on trust, Sztompka (1999) pointed out: "Repeated routines that people follow make it possible to predict their conduct" (Sztompka, 1999: 124) and estimate their "potential trustworthiness" (Sztompka, 1999: 96). Without opportunities to build public familiarity among other inhabitants in a neighborhood, for example, residents may be prone to have mistrust—a lack of clear expectations, predictability, and security (Sztompka, 1999). Public space may also help foster a sense of community because people come together to display and legitimize their identities in the public domain (Holland et al., 2007). Blokland (2003) highlighted the importance of the knowledge that can develop over time through encounters in which people become familiar with each other and begin to distinguish among those who may share similar norms and values.

Finally, this article considers how physical neighborhood structures, such as American public housing communities that are imbued with complex and powerful social stigmas, may shape encounters and interactions, not with other coresidents, but with outsiders. Goffman (1963) described the ways in which people are stigmatized based on assumptions of their moral inferiority. Although stigmas based on race, income, gender, and disability prejudices are familiar, public housing residents (many of whom already belong to a categorized and stigmatized group) may suffer from an additional stigma associated with their place of residence. Vale (2002) described the unique stigma, one that is both person- and place-based, that is applied to residents of America's public housing projects.

The stigma that operates at an individual level through negative associations with a particular person's race, ethnicity, gender, health status, or behavior is reinforced in public housing by powerful group-based and place-based messages. Public housing forces stigmatized people to experience a bounded and stigmatized environment in two mutually reinforcive ways: as a group of buildings and as a system of rules and preferences. The end result of all this is that the physical environment of public housing often reinforces social stigmas by inducing yet another unwelcome form of group identity: that of project resident. (Vale, 2002: 15) 
Because of this unique stigma, public housing communities may shape residents' encounters and interactions with people from outside the neighborhood. Nonstigmatized people may choose not to engage with public housing residents due to this persistent social stigma and how it might make them look to other "normals" (nonstigmatized people) (Goffman, 1963: 30). Thus, stigma may be another important mechanism through which neighborhoods can shape a key foundation for social capital—social networks.

The findings from the literature discussed in this section suggest that several neighborhood factors, including population characteristics, institutions, and stigma, may shape trust, social interaction, and social ties among neighbors. The question of which factors are most significant, combined with the gaps in the understanding of social capital development in the context of relocation, warrants further investigation into the potential role of neighborhoods in promoting or inhibiting relocatees' development of trust and social ties-key foundations for social capital. By further examining the extent to which relocation to different types of neighborhoods shaped perceptions of trust and local social relations, this study seeks to advance the understanding of how social capital may be built in a neighborhood context.

\section{The Study}

This study assesses neighborhood mechanisms for developing social capital, focusing specifically on the role of neighborhood attributes in shaping perceptions of trust, norms, and reciprocity and social interaction for low-income residents who were relocated from a poverty-concentrated public housing neighborhood as part of the HOPE VI Program. The study poses this key research question:

To what extent are neighborhood characteristics important for TNR and for interactions with coresidents and outsiders?

A key contribution of this study is the investigation into neighborhood mechanisms for developing trust and relations in the context of a relocation initiative. Thus, a distinctive component of the study is its systematic comparison of different types of relocatees, which enables the assessment of whether those in mixed-income communities, for example, are more likely to trust their neighbors or report shared norms and reciprocity than are public housing residents. Another notable feature of this study is its mixed methodology, combining both quantitative survey data with qualitative interview data to provide a well-rounded data set on relocatees' experiences in establishing the foundations for social capital in their neighborhoods.

\section{Data Sources and Methodology}

The data for the study were collected as part of a broad longitudinal evaluation of the Maverick Gardens HOPE VI Program in Boston, Massachusetts. ${ }^{5}$ The U.S. HOPE VI Program was established in 1993 to redevelop the "most severely distressed" public housing projects in the nation into new

\footnotetext{
${ }^{5}$ The Center for Urban and Regional Policy at Northeastern University conducted the study between 2002 and 2007.
} 
mixed-income communities of opportunity (HUD, 2008a) (see also Popkin, Katz et al., 2004). ${ }^{6}$ To redevelop these areas, HOPE VI involves the large-scale relocation of residents, most of whom move off site to private-market housing with portable vouchers ${ }^{7}$ or to other traditional public housing developments. Some relocated households return to the new mixed-income housing when it is completed, while others remain permanently off site.

Selected for HOPE VI redevelopment in 2002, Maverick Gardens was originally constructed in 1941 in line with the typical "barracks" style design for public housing built in the United States during that era. The development was located on an 8-acre site at the end of a dead end street, consisted of 12 brick buildings (413 units) with flat roofs surrounded by paved interior walkways, and had no streets running through it. One side of the development abutted a rundown park with remarkable views of Boston Harbor and the city beyond. Its location across the harbor in East Boston meant Maverick Gardens was somewhat isolated from the larger Boston community. To get downtown and to most other Boston neighborhoods, residents had to drive over a bridge or through a tunnel under the harbor (both required a $\$ 3$ toll) or take the subway ( $\$ 3$ round trip). Although its physical location contributed to some feelings of isolation, Maverick Gardens was situated only about two blocks from the bustling Maverick Square, which houses a subway station and numerous restaurants, shops, and services catering to the large local Hispanic population. At the beginning of the HOPE VI program, the Maverick Gardens population was 47 percent Hispanic, 26 percent African American, 15 percent Asian, and 12 percent White (Fitzgerald and Curley, 2003). According to the 2000 U.S. Census, Maverick Gardens was in a census tract with a poverty rate of 43 percent and a non-White population of 50 percent (U.S. Census Bureau, 2000). ${ }^{8}$

The Maverick Gardens HOPE VI Program lasted from 2002 until 2007, with the demolition of buildings and relocation of residents beginning in 2003 and construction ending in 2006. When

\footnotetext{
${ }^{6}$ The program seeks to reduce the concentration of poverty and the housing density in the developments, build housing that blends in with the surrounding community, create streets that connect the developments to the abutting areas, strengthen management, and provide supportive social services (HUD, 2008a). The initiative targets housing developments that suffer from physical deterioration, high rates of crime, chronic unemployment, welfare dependency, inadequate services, and high concentrations of extremely poor residents, minorities, and single-parent families.

${ }^{7}$ The Housing Choice Voucher Program, formerly known as the Section 8 Rental Voucher Program, was created in 1974 to assist "very low-income families, the elderly, and the disabled to afford decent, safe, and sanitary housing in the private market." This portable voucher program enables such households to select their own units in the private market. "The housing voucher family must pay 30 percent of its monthly adjusted gross income for rent and utilities, and if the unit rent is greater than the payment standard the family is required to pay the additional amount" (HUD, 2008b: 2).

${ }^{8}$ Maverick Gardens stands out from many other HOPE VI sites in a number of important ways. First, Maverick Gardens was a relatively small development with fewer units and less density than many other public housing developments around the country. For example, Maverick Gardens had 413 units and no highrise buildings compared with Chicago's Cabrini-Green development, which at one time housed 15,000 people, or Robert Taylor Homes, which housed 27,000 people (see http:// www.thecha.org). In addition, compared with many other public housing communities, Maverick Gardens was not as isolated from transportation and other services and was in a prime real estate location with waterfront views of the downtown urban landscape. The population of Maverick Gardens also differed because nearly one-half of the population was of Hispanic origin; in many other HOPE VI communities residents were predominantly African American (Popkin et al., 2002). Further, the Greater Boston housing market for rentals was among the tightest in the country during the Maverick Gardens HOPE VI Program (2002-07), with relatively high and steadily increasing prices and low vacancy rates (vacancy rates were about 3 percent for the Greater Boston area in the year 2000 compared with the national average of 7 percent) (Comey, Briggs, and Weismann, 2008).
} 
the redevelopment was completed in late 2006 and all new units were occupied, just under one-half of the original 375 households (48 percent) returned to the new mixed-income community, which was renamed Maverick Landing, and slightly more than one-half remained in their relocation units for a variety of reasons related to choices and constraints (see Curley, 2004; Curley and Fitzgerald, 2007). Those who did not return to the site remained permanently off site in other public housing developments (23 percent), with portable vouchers (17 percent), in market-rate housing ( 3 percent), or in homes they purchased ( 2 percent). ${ }^{9}$ This article investigates residents from the three main relocation groups-HOPE VI (the new community), public housing, and voucher users-focusing on their perceptions of trust and their interactions and social tie formation in their neighborhoods. Two key data sources were used: the final post-HOPE VI resident survey and repeated indepth resident interviews.

A longitudinal resident survey was conducted to track changes in resident outcomes over time. The surveys covered a wide range of topics, including relocation, neighborhood conditions, social services usage and service needs, social networks, employment, income, economic stability, and adult and child health. Surveys were implemented before relocation and redevelopment, 1 year later (in the middle of relocation and demolition), and 6 months after the redevelopment was completed. A multilingual staff of sociology and social work graduate students, who had prior survey or community work experience, or both, conducted the survey interviews. ${ }^{10}$ The surveys were translated into Spanish and Vietnamese and interviewers read all questions aloud and recorded respondents' answers on the surveys. They conducted most survey interviews, which lasted about an hour each, in residents' homes and provided respondents a $\$ 25$ gift card to a local supermarket for their time.

This article presents data from the final of the three resident surveys. In 2007, interviewers completed 199 final post-HOPE VI surveys with original Maverick Gardens residents, including 105 who were living in the new mixed-income HOPE VI community, 41 who were residing off site with their vouchers, 40 who were off site in other housing developments, and 13 who were off site in private-market housing, homes they purchased, or the homes of family or friends with whom they were doubling up..$^{11}$ They completed in-person surveys with residents in Spanish (48 percent), English (47 percent), and Vietnamese (5 percent). The sample consisted mainly of female heads of households from a variety of racial/ethnic backgrounds (51 percent Hispanic, 18 percent White, 18 percent African American, 10 percent Asian), about one-half of whom were employed (48 percent). Many respondents had low levels of education (41 percent lacking a high school

\footnotetext{
${ }^{9}$ Another 6 percent of those who relocated were evicted or abandoned their units; the housing authority did not track them.

${ }^{10}$ Interviewers completed a half-day training session that covered topics such as confidentiality procedures, the role of the researcher, accurate data collection, understanding the survey questions, arranging interviews, explaining the study, and overcoming objections. To obtain updates and discuss any issues regarding the survey and completing interviews with residents, the program manager held weekly briefings with all interviewers. As a quality control measure, after selecting a random sample of completed surveys, the program manager phoned the respondents to verify several answers to the survey questions.

${ }^{11}$ Of the 216 baseline survey respondents, 134 completed the final post-HOPE VI survey (a response rate of 62 percent). In addition, to expand the sample of post-HOPE VI respondents and broaden the understanding of a larger number of affected households from the different relocation groups, a supplemental sample of other original Maverick Gardens households who were not surveyed at baseline was added to the final survey. Of the 110 additional residents who were randomly selected, 65 residents completed the post-HOPE VI survey (a response rate of 59 percent).
} 
diploma) and low incomes (66 percent earning less than $\$ 16,000$ a year) (see Curley, forthcoming [2010a]) for further sample demographics). Overall, the survey sample is comparable to the larger population of original Maverick Gardens tenants (in terms of race/ethnicity, employment status, and relocation outcomes, for example).

Linear regression models were used to assess the relationship between neighborhood characteristics and perceptions of TNR. Principal component analyses were conducted with questions regarding trust, norms, reciprocity, and place attachment, and Varimax Rotation clearly showed two scales. ${ }^{12}$ An index of TNR based on the mean response to 11 items (Cronbach's $\alpha=.78$ ) was used as the dependent variable. Respondents were asked, for example, about levels of trust and shared norms among neighbors, whether neighbors were willing to help each other, whether people were respectful and generally got along with one another, and whether people in the neighborhood were capable of solving problems in the neighborhood (see appendix A for a detailed list of all indices). Responses ranged from a low of 0 to a high of 1 . Independent variables included demographics, length of residence, ${ }^{13}$ relocation group, neighborhood satisfaction, and indices of place attachment; neighborhood institutions, facilities, and public spaces; perceived neighborhood problems; and feelings of safety. Place attachment was measured as the mean response to four items assessing the extent to which respondents felt at home in their neighborhood, that it was a good place for them to live, that it was very important for them to live in their particular community, and whether they expected to live there for a long time (Cronbach's $\alpha=.82$ ). Scores ranged from a low of 0 (weak place attachment) to a high of 1 (strong place attachment).

Neighborhood institutions, facilities, and public spaces were assessed with a 15-item index that measured the availability of resources such as churches, employment and job training services, libraries, child care, recreation for youth and adults, afterschool programs, supermarkets, healthcare facilities, transportation, food pantries, and parks or playgrounds in the neighborhood (Cronbach's $\alpha=.74$ ) Index scores ranged from a low of 0 (few resources) to a high of 1 (many resources). Neighborhood problems were measured with a 13-item index (Cronbach's $\alpha=.96$ ) assessing residents' perception of the severity of crime and social and physical disorder in the neighborhood. Responses ranged from a low of 0 (no problem) to a high of 1 (some/big problems). Problems in this index included shootings; attacks/robbery; rape/sexual attacks; people selling drugs; people using drugs; gangs; groups of people hanging out; police not coming when called; graffiti; lack of outdoor lighting; trash in parking lots, sidewalks, and lawns; unattractive common outdoor areas; and lack of recreational space. Safety was measured with an 8 -item index (Cronbach's $\alpha=.79$ ) that assessed feelings of safety and the presence of and satisfaction with police patrols in the neighborhood. Scores ranged from a low of 0 (unsafe) to a high of 1 (safe).

Relocation group was included as an independent variable as a proxy for poverty concentration in participants' neighborhoods. Those who remained permanently relocated with vouchers were

\footnotetext{
${ }^{12}$ Component one included trust, norms, values, reciprocity, and place attachment variables and component two included place attachment variables. For the analysis, the place attachment scale was used separately from the TNR scale.

${ }^{13}$ Length of residence is included because trust and interactions with coresidents are assumed to take time (Coleman, 1988; Saegert and Winkel, 2004).
} 
living in more economically mixed areas (with poverty rates averaging 14 percent), as were those living in the new Maverick Landing HOPE VI community. Although HOPE VI created a "mixedincome" community at Maverick Landing, the current poverty level of the new community is unknown because the most recent U.S. Census was conducted in 2000 (before redevelopment). For purposes of this article, it is assumed that the new Maverick Landing is a more mixed-income neighborhood because many low-income households relocated out of the community and higher income residents moved into the community's new market-rate units. In contrast, people who moved to alternate public housing lived in census tracts with poverty levels averaging 31 percent (compared with the pre-HOPE VI Maverick Gardens census tract, averaging 43 percent below poverty level) (2000 U.S. Census). ${ }^{14}$

In addition to conducting the survey, interviewers repeated indepth interviews with 30 women from the original community over the course of the evaluation; those interviews provided rich data on the effects of HOPE VI and on the processes through which relocation and redevelopment affected residents' lives. Themes covered in the semistructured interviews ranged from social networks, economic stability, and health, but the data relevant for the research question explored in this article center on establishing trust and social connections in the neighborhood. ${ }^{15}$ The sample for the indepth interviews consisted of women who had lived at Maverick Gardens for at least 2 years before the HOPE VI Program began and who were relocated in the first phase of the program. ${ }^{16}$ The indepth interviews were limited to female residents due to the high percentage of female-headed households in public housing. The sample was stratified to include women from the three main relocation groups: 11 onsite movers (37 percent), ${ }^{17} 10$ voucher movers (33 percent), and 9 public housing movers (30 percent). One-half of the women spoke primary languages other than English, and eight were interviewed in Spanish. Participants were recruited for the study via mail, phone, and in-person visits.

The author and a Spanish-speaking ethnographer first interviewed the 30 women in 2004 (1 year after relocation) and conducted followup interviews every 6 to 12 months through the end of the HOPE VI Program evaluation (a total of five rounds of interviews). ${ }^{18}$ They conducted interviews in residents' homes. The tape-recorded interviews lasted between 1.5 and 2.5 hours, and participants were paid $\$ 25$ to $\$ 30$ per interview for their time. Tapes and field notes were transcribed, systematically coded, and analyzed using QSR N6, a qualitative data analysis program. A combined

\footnotetext{
${ }^{14}$ Voucher holders also lived in areas that are less concentrated with racial/ethnic minorities (35 percent on average) than public housing movers (42 percent on average) (compared with the pre-HOPE VI Maverick Gardens census tract, averaging 50 percent non-White).

${ }^{15}$ This qualitative component of the research was also part of a dissertation study that focused particularly on changes in social networks, economic stability, and health and was funded in part with a HUD Doctoral Dissertation Grant (see Curley, 2006, 2009).

${ }^{16}$ During the first phase of relocation (in which 116 households relocated), 41 percent of residents moved on site (to older units that were scheduled for redevelopment in a later phase of the program), 39 percent moved to other public housing, 18 percent moved with vouchers, and 2 percent moved out of subsidized housing altogether.

${ }^{17}$ Because the community was redeveloped in phases, some households were able to relocate on site into older vacant units that were scheduled for demolition in a later phase.

${ }^{18}$ The response rate per interview ranged from 93 percent for the first three interviews to 83 percent for the fourth interview and 80 percent for the fifth.
} 
deductive/inductive approach was used for coding the data according to the research questions and hypotheses regarding changes in social networks and neighbor relations, in addition to allowing themes and concepts to emerge from the data through open coding. Interrater reliability was checked with a colleague who coded a random sample of transcripts using the developed coding scheme.

\section{Findings}

\section{Survey Data}

The post-HOPE VI survey provided interesting data on residents' perceptions of trust, norms, and reciprocity in their current neighborhoods and their perceptions of physical and social disorder, feelings of safety, and the availability of neighborhood institutions, facilities, and public spaces. To assess the relative importance of different neighborhood attributes on perceptions of TNR, linear regression models were used. The TNR index was used for the dependent variable; independent variables included various individual, household, and neighborhood characteristics (most of which were associated with TNR in earlier bivariate tests). ${ }^{19}$ Exhibit 1 presents the final regression model, which included measures of race/ethnicity; language; length of residence; relocation group; neighborhood satisfaction; safety; place attachment; neighborhood problems; and neighborhood institutions, facilities, and public space. This model is very robust-explaining 76 percent of the variance in TNR. The analysis indicates that three factors are statistically significant predictors of TNR: (1) neighborhood institutions, facilities, and public spaces; (2) place attachment; and (3) feelings of safety. Interestingly, none of the demographic and household variables are significantly associated with TNR after controlling for the other variables in the model. The survey also reveals that no significant relationship exists between relocation group (here used as a proxy for neighborhood income mix; see methodology section) and TNR. This finding is in contrast with the policy assumption that creating the right social mix in a neighborhood will produce desired levels of trust and social capital, thereby improving the livability of the neighborhood and life chances of low-income people. This regression model indicates that other factors are more important for TNR than neighborhood type (relocation group).

First, the findings indicate that perceptions of TNR are higher for people who report a greater availability of resources such as neighborhood institutions, facilities, and public spaces in their neighborhood (for each unit increase in neighborhood resources, TNR increased 1.06 points).

Second, place attachment is a significant predictor of TNR. With each unit increase in place attachment, TNR increased .18 points. The data do not establish causality, however, and it is likely that TNR and place attachment reinforce each other. It could be concluded that stronger place attachment leads to greater TNR or shown that, with higher levels of TNR, people develop greater place attachment. The significance of place attachment here is consistent with Kleinhans, Priemus, and Engbersen (2007), who also found a strong relationship between place attachment

\footnotetext{
${ }^{19}$ For a more detailed discussion of bivariate results and a discussion on how different dimensions of social capital (social support, social ties, civic engagement, trust) are interrelated, see Curley (forthcoming [2010b]).
} 


\section{Exhibit 1}

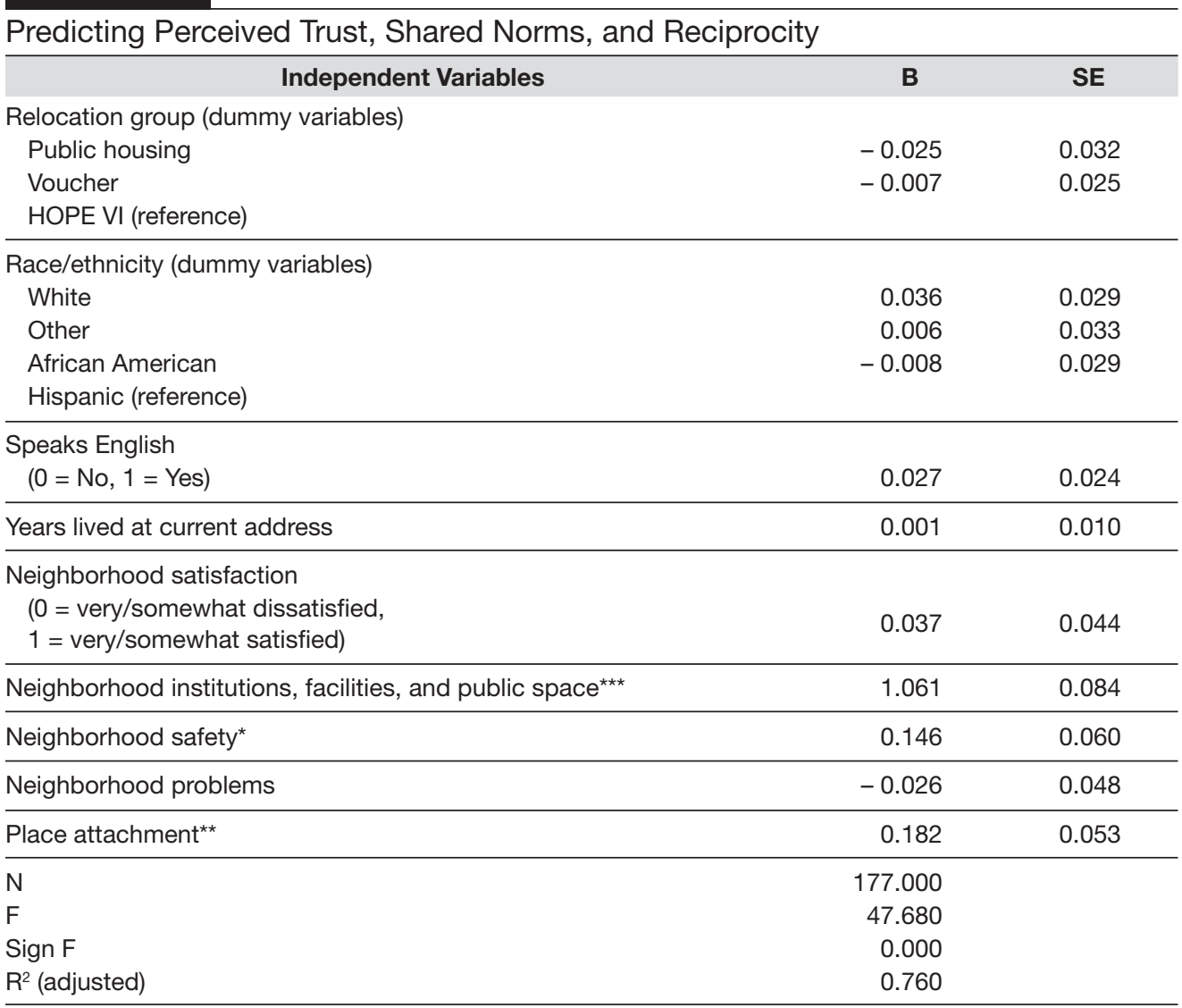

$B=$ unstandardized coefficient. $F=$ F-test. $N=$ number. $S E=$ standard error.

${ }^{*} p<.05,{ }^{* *} p<.01,{ }^{* * *} p<.001$.

and social capita ${ }^{20}$ in their multivariate analyses of survey data in the Netherlands. In an examination of the link between place attachment and individual and neighborhood characteristics in the United Kingdom, Livingston, Bailey, and Kearns (2008) also found a link between what they call social cohesion or social networks and attachment to place. Despite the link between social capital indicators and place attachment having been established in several studies, the direction of causality remains unclear.

Third, safety is also a significant predictor of TNR—with each unit increase in safety, TNR increased .15 points. This finding implies that feeling safe in one's community is conducive to greater levels of trust and positive neighborly relations. Feeling unsafe may have a "chilling effect" on social relationships (Saegert and Winkel, 2004) and consequently lead to social withdrawal (Skogan, 1990). It is also possible, however, that TNR contribute to feelings of safety by strengthening informal social control. Sampson and Raudenbush (1999), for example, found that strong

\footnotetext{
${ }^{20}$ Social capital was measured with indices of social interactions, norms and trust, and associational activities.
} 
collective efficacy (derived from shared norms, trust, and the willingness to intervene for the public good) was associated with lower crime rates-even in high-poverty areas. ${ }^{21}$

\section{Interview Data}

Although the quantitative survey data provide an informative picture of the relative importance of different individual, household, and neighborhood characteristics for TNR, the data cannot explain why neighborhood institutions, facilities, and public space or feelings of place attachment and safety are so important for the development of TNR among neighbors. Data from the indepth interviews with residents provide two important clues about the ways in which neighborhoods shaped social interaction and, therefore, social capital development. First, neighborhood physical structure, local institutions, facilities, and public spaces shaped opportunities for observing and interacting with other neighborhood residents. Second, stigma based on the negative meanings people associate with a neighborhood structure and its residents shaped interactions with outsiders (nonresidents).

\section{Neighborhood Structure, Institutions, and Public Space: Shaping Trust, Interactions, and Ties With Neighbors}

Neighborhood structure and the arrangement of public space were common themes that arose when relocatees talked about getting to know their neighbors and making new ties after relocation to new communities. In describing their encounters and relations with new neighbors, residents often made comparisons with Maverick Gardens, their old public housing community, highlighting the differences in community layout and design and the availability of public space. These differences were particularly salient for those who moved from Maverick Gardens to private-market housing with a voucher. Moving out of Maverick Gardens and into private-market housing meant moving from a community that had a unique built environment. The pre-HOPE VI Maverick Gardens was noticeably different from most other neighborhoods due to numerous features typical of traditional public housing developments in the United States, including the "super-block" arrangement of buildings; the walkways that wove their way throughout the housing development; the unmistakable lack of shops and streets running through the community; the building entryways, hallways, and stairs that were shared by multiple households; the common mail room and management office; and the relatively high population density.

Although the physical arrangement of the buildings and public spaces in the Maverick Gardens public housing community might be described as isolating, stigmatizing, and devoid of "defensible space" (that is, creating safe havens for crime committed by outsiders who can easily evade authorities in such an environment) (Newman, 1972), some features of the built environment were cited by residents as central in shaping neighbor relations, a sense of place attachment and community, and feelings of safety. For example, Nilda, a 23-year-old mother of three children who lived at Maverick Gardens for 4 years before relocation, talked about the sense of belonging and community she experienced at the old Maverick Gardens and how public spaces in the neighborhood facilitated social networks and exchanges with others:

${ }^{21}$ Their work highlights the importance of collective efficacy and informal social control for discouraging unwanted behavior. 
...At Maverick, we used to sit down at the park [across the street]; all the neighbors gathered and had conversations; or [we would] go to the office and talk to the staff. This way we shared, supported each other. ... We were all one family. And we used to get along well. ...We supported each other; we also consulted each other on things that happened to us in Maverick. We helped each other a lot.

These comments suggest that public spaces such as parks and semipublic facilities or institutions such as community centers or even management offices can provide important opportunities for meeting neighbors for conversation and support. As discussed later in this article, however, some influential factors can also limit the uses of such spaces in a neighborhood.

The resident interviews uncovered numerous other examples of how the spatial arrangement of neighborhood buildings, facilities, and public spaces can influence the likelihood and frequency of contact among neighbors. The old Maverick Gardens community, by housing many families in close quarters and with its particular neighborhood structure, inevitably led to repeated occasions for observations and interactions with neighbors. This environment fostered social ties that were "multiplex" and had intergenerational closure; for example, an environment where children's friends were the children of their parents' friends (Coleman, 1988). These dense, overlapping networks enhanced residents' support systems and contributed to their collective efficacy (Sampson, Raudenbush, and Earls, 1997) because residents knew each other's children and often felt a shared responsibility to monitor them (for example, from apartment windows) and report misbehavior to their parents. As Josie's comments suggest, these spatial and social dimensions of the environment at Maverick Gardens also contributed to feelings of belonging and safety and accommodated neighbors' supportive exchanges:

...Well, in Maverick you knew everybody. You knew each other's kids, you knew their parents, their cousins, their uncles. So everywhere you went, everybody knew who you was. So you felt fine. ...You knew everything that happened at Maverick. ... It's like Maverick is just one big bubble.

...Upstairs, downstairs, across the hall, three buildings over. ... That's the thing you liked about living in a small place like that. You can go three doors over and be like, "Can I borrow a cup of sugar?"

Living in a high-density community like Maverick Gardens, where common areas and public spaces encouraged (or even required) recurring encounters with the same people daily, meant that most residents were well informed on who belonged in the area and who did not. In essence, the arrangement of buildings and public spaces promoted public familiarity (Lofland, 1998). Although public familiarity may remain at the level of mere facial recognition of neighbors, for many of the Maverick Gardens residents in this study it led to more meaningful repeated social interactions, the development of social ties, and a sense of belonging. Some residents were deeply affected by the loss of community that occurred with the HOPE VI redevelopment, and their comments indicated that the altered population of residents at Maverick Landing (a mix of old and new residents) and the change in the use of shared public space played a role. Thus, the residents who returned to the rebuilt mixed-income Maverick Landing community connected their altered social environment with the changes that were made to the built environment. As one resident explained: 
...no one sits around outside on the porch and talk. Things are different now. Even my old neighbors that I knew [before] that live in this building don't talk. No one stops to talk anymore.

Other residents discussed the change to the social environment and the change in residential behavior. In contrast to the old community, where many residents had a habit of leaving their doors open for casual conversation and air to flow in and out, residents in the new Maverick Landing kept their doors shut and locked. As one resident said:

I was very sad to see my old apartment go. ... Because everyone knew everyone and you didn't lock your doors behind you. Now no one wants to know anyone-they shut their doors and stay to themselves.

Some residents talked about how at the old Maverick Gardens, when the weather was nice, people would put out lawn chairs and plastic kiddie pools in the small paved areas outside the building entrances. There they would spend long hours together as their children played and they enjoyed conversations outdoors. Although the public spaces in the old community were far from glamorous, residents had a lot of flexibility in how they used them and they often made the most of these spaces. The new Maverick Landing, in contrast, contains two well-designed public spaces: a spacious courtyard with attractive stonework design, pleasant greenery, and walls for seating and a new plaza with a fountain located in front of a small new park and community center at one edge of the development. In addition, the entire built environment is different: the new neighborhood consists of townhouse style homes with individual front porches and small, fenced front yards and two midrise buildings with shared entryways. The quality of all of these spaces (public, semiprivate, and private) improved dramatically with the HOPE VI redevelopment; however, many returning Maverick Gardens residents rarely used them because of the constraints placed on the uses of these new spaces. The management office of the new community put into effect strict rules for the uses of public spaces and personal outdoor spaces (see also Graves, 2008). Curfews were stringently enforced for the courtyards (one of which the management office overlooked), biking on the property was forbidden, restrictions were placed on music, and loitering was prohibited in hallways and lobbies of buildings. The rules also forbade residents from personalizing their front doors with decorations and from placing furniture and outdoor children's toys on front porches or in public spaces outside entryways. Many residents thought these rules discouraged their use of these shared spaces, leading them to spend less time in areas where they could engage with other residents. ${ }^{22}$ In essence, although Maverick Landing is now sparkling and new, management regulations have reduced opportunities for public familiarity, trust, and social relations to develop among residents in the new community by limiting the uses of both public and private outdoor spaces. ${ }^{23}$

\footnotetext{
${ }^{22}$ On a similar note, Collins et al. (2005) also found that residents of another HOPE VI site did not frequently use their new community center that was built as part of the new community because they felt it was not "theirs." In contrast with the old community center that was well worn and bustling with children and adults most days, the new community center was plain, lacked permanent furniture, and had new time and use regulations.

${ }^{23}$ In her ethnographic study of social relations in the mixed-income Maverick Landing community, Graves (2008) provides a detailed account of the ways in which management discouraged interactions among residents (including structuring and enforcement of the community rules).
} 
Although the physical structure and public spaces of the old Maverick Gardens public housing development contributed to many residents' tight-knit social networks, their attachment to the community, their feelings of safety, and their sense of belonging, others thought the same neighborhood structure reduced their privacy. The high concentration of resource-poor residents combined with the structural characteristics of public housing communities also contributed to the development of "draining" social ties for some residents (see Curley, 2009 for a detailed discussion about these draining ties). Several relocatees who moved to private-market housing with vouchers talked about how moving away from "the projects" eliminated the hassle of neighbors constantly being involved in each other's "business" and enhanced feelings of privacy. Relocating out of Maverick Gardens, then, provided some residents the opportunity to step back and regain their sense of privacy and anonymity. Katherine, a mother of two teenage daughters who moved with a voucher explained:

For me-it's good [here]....I don't like bothering with other people; I don't like other people knowing my business-I like it. When you live in the projects, it's like—don't get me wrong, I'm not putting it down-that's where I grew up. But you got like all these different smells from all these different foods, everybody who blares their stereo, who's slamming their door, who's yelling at their kids, or who's knocking on your door to use your phone or borrow something, or who's looking out the door to see when you bought something or when you're having company-I don't miss that at all. It's a total different way of living, you know-it's not my own house but I have my own space [here]. It's bright, it's private, my landlord—he doesn't bother me.

For Jocelyn, a single mother of two boys who moved to a residential neighborhood in Boston with a voucher, the peace and quiet of the area and the distinct privacy it granted her were similarly welcome reprieves. The street to which she moved was entirely residential and, although she could no longer send her 10-year-old son to get something at the corner store (because there were no stores nearby) and the neighborhood offered little opportunity for social interaction, she was satisfied with the community. Even after living in her new neighborhood for 3 years, she knew only one neighbor by name (her landlord who lives in the downstairs apartment of the two-family home) and could recognize the faces of only three others on the street. Her level of comfort and feeling at home in the neighborhood, however, may be closely tied to the public familiarity she has developed on her street. Everyday, an unmarked space on the sidewalk across the street turns into the school bus stop for her son and three other neighborhood children. In this undefined public space, whose use is transformed only briefly twice a day as children are picked up in the morning and dropped off in the afternoon, public familiarity is established with other parents who wait with their children. Through such repeated encounters, whether they are at the bus stop, the grocery store, or the nearby park, people can gain an awareness of neighbors and their everyday routines. Although their encounters may appear to be routine and mundane and their relationships may remain informal, the public stage through which they observe each other helps build familiarity (Blokland, 2003; Lofland, 1973, 1998). Although Jocelyn knew the other parents only by face, enough trust and familiarity developed through these repeated encounters to the point where she felt confident that they would watch her son when she sent him to the bus stop alone some mornings. Jocelyn was pleased with this spatial structure of the neighborhood and she valued the privacy it afforded her. Although this same configuration might lead others to feel lonesome 
and isolated, for Jocelyn, who had a supportive social network of relatives and friends who lived elsewhere (and with whom she visited regularly by car), her minimal contact with neighbors was sufficient, and she found it a pleasant place to live.

Other voucher holders also recognized the different interaction patterns among neighbors in their new communities and attributed these to the spatial differences of their neighborhoods. Josie, a single woman in her mid-30s, moved with her voucher to an adjacent community just north of Boston. She rented an apartment on the third floor of a three-family house on a residential side street that consisted of mostly other two- and three-family homes. When asked about her new neighbors (whether she had gotten to know them at all, socialized with them, etc.), Josie explained that, because many residents in her new neighborhood own their homes and have their own yards, they do not congregate in public places_outside entrances or in parks—as her old neighbors did at Maverick Gardens. She said, "Since everybody in Chelsea has a house, they tend to stay on their own property and do what they want to do." In essence, the spatial arrangement of her new neighborhood did not facilitate encounters the way her old public housing community did (see Josie's comments about the old community earlier in this article). Although she too enjoyed the newfound sense of privacy, she was equally frustrated with the lack of opportunities to get to know her new neighbors.

Shakira, a single mother of three school-age boys who also moved to private-market housing with a voucher, similarly offered a spatial explanation for her lack of knowledge about neighbors in her new community:

You don't see a lot of people just hanging out [here]. Everybody's like stays to themselves. They don't bother nobody. ... guess when you're living in the projects, you see a lot of people coming out.

The lower population density in her new community and the arrangement of homes with their individual back porches and yards were in stark contrast to Maverick Gardens, the high-density public housing development she had moved from, where 12 or more households departed and entered from the same entryway every day and where children and mothers frequently gathered on the front steps or on the park benches across the street.

Although many relocatees appreciated the newfound privacy that came with the structure of their new neighborhoods, at the same time, many experienced increased isolation and talked about how the neighborhood spatial arrangements impeded their ability to get to know their neighbors or make new ties. Nilda became lonely and frustrated with her lack of interaction with neighbors in her new community, and she suggested that the absence of shared public space played a role:

The neighbors here are quiet; they are always inside their apartments. They don't share. I don't like that. Maybe it's because we don't have any park around here where we can sit and talk. ... Here-I don't know my neighbors. ... Life is very sad here. But people don't let me get close to them. When I go out I say "hi" and that is it.

Nilda's comments suggest that without public spaces such as parks, neighbors may have little opportunity to develop public familiarity, meet one another, establish social ties, or build a sense of community. Public spaces and local facilities may be so essential because they enable people who 
repeatedly encounter one another to have brief exchanges or more lengthy conversations without the efforts and obligations required of more formal meetings.

\section{Neighborhood Structure: Shaping Interaction and Ties With Outsiders}

In addition to shaping encounters and relations within a community, neighborhood structure and public space can also influence encounters and relations with people from outside the community. The distinguishable structure of public housing neighborhoods was cited by residents as severely limiting their interactions with nonresidents-precisely the types of people thought to be lacking from the social worlds of low-income people living in high-poverty neighborhoods-due to the heavy social stigma associated with public housing communities and their residents. Some residents carefully negotiated relations with "outsiders" to avoid revealing their residence in a public housing development and the rejection, embarrassment, and humiliation that could accompany such a revelation. Stephanie, a mother of three children who relocated to a different public housing development, hated the fact that she lived in a community that was so stigmatizing. She talked about the stark physical image of her current public housing community, a development built in the typical "barracks style" of the 1950s that has an ominous feel both on the interior and exterior. Although Maverick Gardens was similar in its brick superblock construction, this housing development was different because it was located on the edge of a steep hill that had a large cross (50 feet high) rising from a vacant lot (owned by a church) at the edge of the development. "What I don't like is that it's up on the hill. I don't know-it looks like some kind of crazy asylum with the cross like that." Stephanie went on to explain how her fear of being judged by where she lives influences her relations with people from the outside:

People see the projects... and there is a prejudgment that comes along with that. And I don't know-unfortunately, the majority right off the bat consider you to be a piece of shit. So you know, I don't know which one is gonna be like 'you know, it's just lowincome-they just don't make that kind of money.' And I don't know which parents are gonna say like, "piece of shit." So I know that I try to protect my kids all the way.

Thus, neighborhood physical structures are not neutral, because people attribute meanings to them. Stephanie's comments illustrate how the physical structure of public housing projects, by carrying such a strong negative stigma, results in prejudice toward the individuals residing there and can have a negative effect on their access to social capital (that is, by shaping their encounters and ties with others). She alludes to the different uses of public spaces in these communities contributing to the negative image and social stigma attached to all its residents:

... And the ones that I see hanging out [in public spaces], they're drinking, they're swearing, they're smoking. And what I don't like is there is a place and time to do that; go to the bar. Get your drink over there. But that's part of living here. And then it makes me look ignorant when company comes.... when you're hanging out and you're drinking with Christmas lights and there is a barbecue out front and I bring somebody over or my kids bring someone over-we're not only looking poor-because you can clearly tell what the projects look like. You automatically know my income when you see the building. So I hate that there is no lying about it. 
In public housing communities, where density is high and private space is severely limited (that is, large households living in small apartments where meals are sometimes eaten in shifts due to limited seating or table space), residents are more likely to engage in "private" behaviors in public spaces (Sánchez-Jankowski, 2008). Although the activities Stephanie described might be acceptable if undertaken in the private backyards of the middle-class, these same activities and behaviors are viewed differently for the poor who must display them in shared spaces. Because of these different uses (or misuses) of public spaces in her public housing community and its discernible neighborhood structure, Stephanie manages her relationships and her children's relationships with outsiders to avoid the disclosure of information regarding their place of residence. In the past, such disclosure had produced a significant amount of embarrassment and was pivotal in marking the end of establishing relationships. One tactic she used was forbidding her daughter from inviting classmates to her house after school (although she allowed her daughter to play at others' homes) and not allowing her daughter to accept rides home from her schoolmates' parents so as not to reveal that they lived in "the projects." This pattern of avoidance is consistent with Goffman's theory of stigma: "... the tendency for a stigma to spread from the stigmatized individual to his close connections provides a reason why such relations tend either to be avoided or to be terminated" (Goffman, 1963: 30).

Another woman, Gianna, who moved to the same public housing neighborhood as Stephanie, thought that the physical characteristics of the area affected her contact with her preexisting network of friends and family. Gianna's ties described her community as "the dungeons," in part, because it is a bleak-looking community and quite isolated from transportation, stores, facilities, and other conveniences. She explained:

Well, it [relocation] changed my life because over there [at Maverick]... I had like close friendships with people. When I moved here, I lost contact with all the people from Maverick. ...For some people that I used to see over there, they think I moved so much further away. I don't know why. ... My nieces and them, they used to get off at the train and just walk down. But nobody likes getting off [here] and walking up. Even the ones that drive, they feel like I am living in the dungeons.

Although Maverick Gardens also stood out in its stark appearance, Gianna's family and friends were willing to visit because it was near the train—and not isolated on top of a hill. Gianna's and Stephanie's experiences indicate that the physical structure of a neighborhood, its spatial arrangements, facilities, and public spaces can have implications not only for interactions with coresidents but also for interactions with outsiders. Therefore, by shaping social networks, and thus access to social capital, stigmatization can play an important role in the social reproduction of inequalities. ${ }^{24}$

The findings indicate that the structural arrangements of high-density public housing communities can enhance social interactions with coresidents, which can lead to the development of social capital. The social capital accessed through ties to low-income neighbors, however, may be more

\footnotetext{
${ }^{24}$ See Sampson (2009) for a discussion of how perceptions of disorder, because they are largely shaped by social context and perceptions of disorder among others, play an important role in a cyclical process that reinforces societal stigmas based on racial prejudices and contributes to the reproduction of inequalities.
} 
of the supportive type that helps people "get by" in life rather than the leveraging type of social capital that helps people "get ahead" (Briggs, 1998). At the same time, the same neighborhood structure, combined with a high concentration of resource-poor residents, can lead to the development of draining social ties, which can hinder the development of both supportive and leveraging social capital. The question raised by this study is whether relocation out of such communities can improve residents' access to social capital. Most relocatees in this study had formed very few social ties within their new neighborhoods during the 2 to 3 years following their relocation. Thus, residents' access to social capital was not obviously improved through relocation to different types of neighborhoods. The findings suggest, however, that particular neighborhood attributes were important for the development of social trust and public familiarity in the neighborhood, which are important foundations of social capital and could lead to the development of social ties over a longer period of time.

\section{Discussion}

This study explored the factors that contribute to low-income residents' development of trust and social relations - the foundations of social capital. Both quantitative and qualitative methodologies helped uncover an important and understudied connection among trust, norms, reciprocity, interactions, and encounters on the one hand and neighborhood structure, facilities, institutions, and public spaces on the other. Multivariate analysis identified the significance of the availability of these neighborhood resources and, to a lesser extent, feelings of place attachment and safety, because neighborhood attributes mattered more for TNR among neighbors than all other individual, household, and neighborhood factors examined. The residents in the study who had access to more neighborhood institutions and public spaces (and who had greater feelings of place attachment and safety) were significantly more likely to trust their neighbors and perceive shared norms and reciprocity among coresidents in their communities. Data from the indepth interviews with residents living in different types of housing and neighborhoods were used to better understand some of the patterns found in the survey data. This rich qualitative data revealed that neighborhood resources were important for generating and sustaining trust and social relations. It was precisely through such institutions and public spaces that residents could observe and interact with their neighbors and where they developed and maintained social ties in the community. In addition to this rather straightforward process, local facilities and public spaces can also generate trust and shared norms among neighbors in a more subtle way: by providing the stage for public familiarity to develop. Repeated encounters in such spaces can build public familiarity as people gain valuable information about each other (that is, about habits and patterns of living) that enable them to identify (or not identify) with a group (Blokland, 2003; Lofland, 1973; Sztompka, 1999). Institutions and public spaces, including childcare centers, parks, libraries, and recreation facilities, offer places where residents can congregate both informally and formally and observe each other in public. These repeated encounters in such spaces can generate public familiarity, a basic component of trust (Sztompka, 1999). Neighborhoods devoid of shared public spaces and institutions may leave residents with few opportunities to observe each other in this way, and, as a result, residents may be more likely to have mistrust—a lack of clear expectations, predictability, and security (Sztompka, 1999) and may be less likely to develop relationships with their neighbors. 
In addition to shaping the development of trust and interactions among coresidents, neighborhood structures, according to the findings, can also influence the development of relations with outsiders. This was the case for public housing residents who reported that the profound social stigma associated with public housing, combined with the inescapable stark appearance of their neighborhood's structure, weighed heavily on their encounters and relations with people from outside their community. Ironically, although the physical structure of the pre-HOPE VI Maverick Gardens community often contributed positively to the development of trust, interactions, and social ties among many coresidents, the same physical form negatively affected residents' ability to form relations with nonresidents (and contributed to overbearing, draining relationships with neighbors for some).

\section{Policy Implications and Future Research}

Transforming poverty-concentrated housing developments into mixed-income or mixed-tenure communities has become popular policy practice in the United States and in Western Europe, Australia, and Canada. Aside from the improvements in housing quality, one expectation of this approach is that lower income people living in a more mixed environment will have greater access to social capital. Contrary to this expectation, numerous studies have found that such initiatives do not produce anticipated effects on at least one prerequisite for social capital—social networks. The current research suggests that this approach may also not have the desired effect on another important foundation of social capital—trust, norms, and reciprocity. The evidence from this study indicates that these prerequisites for social capital depend not on neighborhood poverty concentration but on neighborhood facilities and public spaces, the feeling of attachment to place, and the feeling of safety. Thus, the connection between income mix and social capital made by some policymakers and academics may be overstated. ${ }^{25}$ The qualitative evidence from the current study confirms that spatial arrangements of neighborhoods, public spaces, and facilities are significant for residents' encounters with others and, subsequently, for the development of public familiarity, trust, and social relations in neighborhoods. Simply relocating residents to lower poverty areas does not result in relocatees being well integrated or enmeshed in rich, new social worlds that provide them with access to social leverage and upward mobility opportunities. Rather than simply trying to place residents in communities with the "right" social mix, a more effective strategy for encouraging the development of social capital may be building, preserving, and improving public spaces, facilities, and institutions that serve a variety of residents; making communities safe; fostering a sense of community and attachment to place; and providing residents opportunities to observe and meet one another. ${ }^{26}$ Housing programs like HOPE VI that seek to improve prospects for upward mobility should move beyond the fixation on mixed neighborhoods and lower poverty rates by broadening the definition of desirable neighborhoods to include "opportunity areas" (Briggs, 2006): resource-rich areas with ample social supports, good-quality services, institutions and public spaces, transportation, schools, and entry-level jobs with career ladders.

\footnotetext{
${ }^{25}$ Dekker and Bolt (2005) similarly found that socioeconomic status (that is, higher income and more education) was not associated with strong levels of social capital, suggesting that social mixing may be "a counter-intuitive strategy to strengthen social cohesion" (Dekker and Bolt, 2005: 2468).

${ }^{26}$ Although not the focus of this article, encounters in public space could possibly lead to or enhance existing tensions and conflicts among groups in a neighborhood.
} 
Improving neighborhood resources for lower income people may be particularly important not only because of the potential effect on public familiarity, trust, and social ties (and therefore social capital) but also for the simple fact that high-quality services and resources can compensate for lower individual resources. Further, quality and accessible resources in the neighborhood may reduce the likelihood of low-income residents "draining" or being drained by other lower income people (Curley, 2008). Finally, the important functions of public space in promoting familiarity, trust, norms, and social contacts should be kept in the forefront of any discussion of urban redevelopment. For example, public spaces can be designed as friendly places with design features and seating arrangements that promote flexible use and maximize potential opportunities for repeated encounters, observations, and interactions (Whyte, 1988). Public spaces can play an important role in enhancing everyday life in communities, and policies and initiatives that support or allow the privatization of public spaces in urban areas must also consider how these changes may negatively affect a community's social fabric (Holland et al., 2007). ${ }^{27}$

A key contribution of this study is that it highlights the significance of neighborhood resources for the development of social capital. Although previous research has suggested that neighborhood institutions are important for the stability of communities, few studies have considered the role neighborhood structure, local facilities, and public spaces play in the social capital-building process among residents. Thus, future research and policy discussions on social capital and neighborhoods should carefully consider physical structure, local institutions, and public spaces. More qualitative and quantitative research is needed to further assess the role of different types of neighborhood resources and determine whether certain institutions or public spaces better provide more useful meeting places, better promote familiarity and trust, or provide greater access to resources or other social capital-building opportunities. Future studies could also investigate the extent to which different design features of public spaces, neighborhood structures, and facilities promote or inhibit encounters with other residents and with nonresidents.

\section{Appendix A Index Measures}

Trust, norms, and reciprocity (TNR)

(11-item index, Cronbach's $\alpha=.78$ )

Scores ranged from a low of 0 to a high of 1 . (True/false, coded $1 / 0$ [reverse coded as necessary])

1. My neighbors and I want the same things from this neighborhood.

2. I care what my neighbors think of my actions.

3. Most of the residents in this neighborhood are respectful of their neighbors.

4. People in this neighborhood can be trusted.

5. People living here do not share the same values.

\footnotetext{
${ }^{27}$ See Smith (1996) and Lofland (1998) for further discussion on the privatization and regulation of public space. Smith warns that in many cities public spaces have been transformed, purified, and privatized to accommodate and attract new, higher income urban dwellers, investors, and tourist consumers.
} 
6. People living in this neighborhood generally do not get along with each other.

7. I have no influence over what this neighborhood is like.

8. If there is a problem in this neighborhood people who live here can solve it.

9. People around here are willing to help their neighbors.

10. I can recognize most of the people who live in this neighborhood.

11. Very few of my neighbors know me.

Neighborhood institutions, facilities, and public spaces (15-item index, Cronbach's $\alpha=.74$ ) Scores ranged from a low of 0 (few resources) to a high of 1 (many resources). Are the following services available in your neighborhood? (yes [1]/no [0])

1. Health care.

2. Afterschool programs.

3. Supermarket/grocery.

4. Recreation for youth.

5. Recreation for adults.

6. Childcare.

7. Churches.

8. Library.

9. Transportation.

10. Employment services.

11. Job training.

12. Food pantry.

13. Parks or playgrounds.

14. Lack of social services in the neighborhood (some/big problem [0] vs. no problem [1]).

15. Have you needed any services and not been able to get them? (yes [0]/no [1]).

Place attachment (4-item index, Cronbach's $\alpha=.82$ )

Scores ranged from a low of 0 (negative) to a high of 1 (positive).

1. I think this neighborhood is a good place for me to live.

2. I feel at home in this neighborhood.

3. It is very important to me to live in this particular community.

4. I expect to live in this neighborhood for a long time.

Safety index (8-item index, Cronbach's $\alpha=$.79)

Scores ranged from a low of 0 (unsafe) to a high of 1 (safe).

1. Do you feel safe in the neighborhood? $(\mathrm{y} / \mathrm{n})$

2. Do police patrol neighborhood? (y/n)

3. Satisfaction with police patrols. $(y / n)$ 
4. Do the police come when called?

5. I feel physically safe in this neighborhood (true/false).

6. Residents in this neighborhood worry about illegal activities occurring in the neighborhood.

7. People living in this neighborhood worry about being physically attacked.

8. Residents in this neighborhood do not worry about stealing or thefts.

Neighborhood problems (13-item index, Cronbach's $\alpha=.96$ ) (some/big problem [1] vs. no problem [0]) [Scores ranged from 1 (some/big problem) to 0 (no problem)?]

1. Shootings.

2. People being attacked/robbery.

3. Rape/sexual attacks.

4. People selling drugs.

5. People using drugs.

6. Gangs.

7. Groups of people just hanging out.

8. Police not coming when called.

9. Graffiti.

10. Lack of outside lighting.

11. Trash in parking lots, on sidewalks, and on lawns.

12. Unattractive common outdoor areas.

13. Lack of recreational space.

\section{Acknowledgments}

This research was funded in part through a U.S. Department of Housing and Urban Development Doctoral Dissertation Research Grant and the Boston Housing Authority. The author thanks the residents of Maverick for their participation and colleagues at OTB for their helpful comments on an earlier version of this article.

\section{Author}

Alexandra M. Curley is a guest researcher in the Department of Urban Renewal and Housing at the OTB Research Institute for Housing, Urban and Mobility Studies at Delft University of Technology in The Netherlands. 


\section{References}

Blokland, Talja. 2003. Urban Bonds. Cambridge, United Kingdom: Polity.

Blokland, Talja, and Floris Noordhoff. 2008. "The Weakness of Weak Ties: Social Capital To Get Ahead Among the Urban Poor in Rotterdam and Amsterdam." In Networked Urbanism: Social Capital in the City, edited by Talja Blokland and Mike Savage. Aldershot, United Kingdom: Ashgate: $105-125$.

Bourdieu, Pierre. 1986. "The Forms of Capital." In Handbook of Theory and Research for the Sociology of Education, edited by John Richardson. New York: Greenwood Press: 241-258.

Briggs, Xavier de Souza. 2006. "Assisted Housing Mobility and the Success of Low-Income Minority Families: Lessons for Policy, Practice and Future Research," Northwestern Journal of Law and Social Policy 1 (1): 25-61.

1998. "Brown Kids in White Suburbs: Housing Mobility and the Many Faces of Social Capital," Housing Policy Debate 9 (1): 177-221.

Briggs, Xavier de Souza, Elizabeth Cove, Cynthia Duarte, and Margery Austin Turner. 2007. "How Does Leaving High Poverty Neighborhoods Affect the Employment Prospects of Low Income Mothers and Youth? Evidence from the Moving to Opportunity Experiment." In Three-City Study of Moving to Opportunity. Working paper \#3. Cambridge, MA: Massachusetts Institute of Technology: $1-29$.

Brophy, Paul, and Rhonda Smith. 1997. "Mixed-Income Housing: Factors for Success," Cityscape: A Journal of Policy Development and Research 3 (2): 3-31.

Buron, Larry, Susan J. Popkin, Diane Levy, Laura E. Harris, and Jill Khadduri. 2002. The HOPE VI Resident Tracking Study. Washington, DC: Urban Institute.

Clampet-Lundquist, Susan. 2004. "Hope VI Relocation: Moving to New Neighborhoods and Building New Ties," Housing Policy Debate 15 (2): 415-47.

Coleman, James S. 1988. "Social Capital in the Creation of Human-Capital," American Journal of Sociology 94: 95-S120.

Collins, Mary E., Alexandra M. Curley, Cassandra M. Clay, and Rita Lara. 2005. "Evaluation of Social Services in a Mixed-Income Housing Development," Evaluation and Program Planning 28 (1): $47-59$.

Comey, Jennifer, Xavier de Souza Briggs, and Gretchen Weismann. 2008. Struggling to Stay Out of High-Poverty Neighborhoods: Lessons from the Moving to Opportunity Experiment. Metropolitan Housing and Communities Center Policy Brief. Washington, DC: Urban Institute.

Curley, Alexandra M. Forthcoming (2010a). "HOPE VI—A Viable Strategy for Improving Neighborhood Conditions and Resident Self-Sufficiency," Housing Policy Debate.

. Forthcoming (2010b). "Relocating the Poor: Social Capital and Neighborhood Resources," Journal of Urban Affairs. 
2009. "Draining or Gaining? The Social Networks of Public Housing Movers in Boston," Journal of Social and Personal Relationships 26 (2-3): 227-247.

- 2008. "A New Place, a New Network? Social Capital Effects of Residential Relocation for Poor Women." In Networked Urbanism: Social Capital in the City, edited by Talja Blokland and Mike Savage. Aldershot, United Kingdom: Ashgate: p. 85-103.

_ 2006. "Hope and Housing: The Effects of Relocation on Movers' Economic Stability, Social Networks, and Health.” Ph.D. Diss., Department of Sociology, Boston University.

—. 2004. "Maverick Gardens HOPE VI Evaluation: Findings from In-Depth Interviews on Phase I Relocation." Boston: Northeastern University, Center for Urban and Regional Policy.

Curley, Alexandra M., and Joan Fitzgerald. 2007. "All We Hoped For? Maverick HOPE VI Final Resident Survey Results." Boston: Northeastern University, Center for Urban and Regional Policy.

Dekker, Karien, and Gideon Bolt. 2005. "Social Cohesion in Post-War Estates in the Netherlands: Differences between Socioeconomic and Ethnic Groups," Urban Studies 42 (13): 2447-2470.

Dekker, Karien, and Masa Filipovic. 2008. "The Influence of Physical Measures on Social Cohesion in Large Housing Estates: Case Studies in the Netherlands and Slovenia Compared." In Restate, Second Edition, edited by Ronald van Kempen, Karien Dekker, Stephen Hall, and Ivan Tosics. Bristol, United Kingdom, Policy Press.

Dominguez, Silvia, and Celeste Watkins. 2003. "Creating Networks for Survival and Mobility: Social Capital among African-American and Latin-American Low-Income Mothers," Social Problems 50 (1): 111-135.

Fischer, Claude S. 1982. To Dwell among Friends: Personal Networks in Town and City. Chicago: The University of Chicago Press.

Fitzgerald, Joan, and Alexandra M. Curley. 2003. "First Year Evaluation of the Boston Housing Authority's HOPE VI Project at Maverick Gardens.” Boston: Northeastern University, Center for Urban and Regional Policy.

Fulkerson, Gregory M., and Gretchen H. Thompson. 2008. "The Evolution of a Contested Concept: A Meta-Analysis of Social Capital Definitions and Trends (1988-2006)," Sociological Inquiry 78 (4): 536-557.

Goffman, Erving. 1963. Stigma: Notes on the Management of Spoiled Identity. Upper Saddle River, NJ: Prentice-Hall.

Granovetter, Mark. 1973. "Strength of Weak Ties," American Journal of Sociology 78 (6): 1360-1380.

Graves, Erin. 2008. "Constructing Community: Class, Privatization, and Social Life in a Boston Mixed-Income Housing Development." Ph.D. Diss., Department of Urban Studies and Planning, Massachusetts Institute of Technology.

Greenbaum, Susan. 2002. "Social Capital and Deconcentration: Theoretical and Policy Paradoxes of the HOPE VI Program," North American Dialogue 5 (1): 9-13. 
Guest, Avery M., and Susan K. Wierzbicki. 1999. "Social Ties at the Neighborhood Level: Two Decades of GSS Evidence," Urban Affairs Review 35 (1): 92-111.

Holland, Caroline, Andrew Clark, Jeanne Katz, and Sheila Peace. 2007. Social Interactions in Urban Public Places. Bristol, United Kingdom: Joseph Rowntree Foundation.

Kleinhans, Reinout. 2004. "Social Implications of Housing Diversification in Urban Renewal: A Review of Recent Literature," Journal of Housing and the Built Environment 19: 367-390.

Kleinhans, Reinout, Hugo Priemus, and Godfried Engbersen. 2007. "Understanding Social Capital in Recently Restructured Urban Neighbourhoods: Two Case Studies in Rotterdam," Urban Studies 44 (5-6): 1069-1091.

Kleit, Rachel G. 2001. "The Role of Neighborhood Social Networks in Scattered-Site Public Housing Residents' Search for Jobs," Housing Policy Debate 12 (3): 541-573.

Kling, Jeffrey, Jeffrey Liebman, and Lawrence Katz. 2005. "Experimental Analysis of Neighborhood Effects," Econometrica 75 (1): 83-119.

Lin, Nan, and Mary Dumin. 1986. "Access to Occupations through Social Ties," Social Networks 8 (4): 365-385.

Livingston, Mark, Nick Bailey, and Ade Kearns. 2008. People's Attachment to Place-The Influence of Neighbourhood Deprivation. Glasgow, Scotland: Joseph Rowntree Foundation.

Lofland, Lyn H. 1998. The Public Realm: Exploring the City's Quintessential Social Territory. New York: Aldine De Gruyter.

1973. A World of Strangers: Order and Action in Urban Public Space. New York: Basic Books.

McPherson, Miller, Lynn Smith-Lovin, and James M. Cook. 2001. "Birds of a Feather: Homophily in Social Networks," Annual Review of Sociology 27: 415-444.

Mok, Diana, Barry Wellman, and Juan Antonia-Carrasco. 2008. "Does Distance Matter in the Age of the Internet?" Paper presented at International Sunbelt Social Network Conference, St. Petersburg, Florida, January 22-27, 2008.

Morenoff, Jeffrey D., Robert J. Sampson, and Stephen W. Raudenbush. 2001. "Neighborhood Inequality, Collective Efficacy, and the Spatial Dynamics of Urban Violence," Criminology 39 (3): 517-558.

Newman, Oscar. 1972. Defensible Space. London, United Kingdom: The Architectural Press.

Orr, Larry, Judith Feins, Robin Jacob, Erik Beecroft, Lisa Sanbonmatsu, Lawrence Katz, Jeffrey Leibman, and Jeffrey Kling. 2003. "Moving to Opportunity Interim Impacts Evaluation." Washington, DC: U.S. Department of Housing and Urban Development.

Peterson, R.D., L.J. Krivo, and M.A. Harris. 2000. "Disadvantage and Neighborhood Violent Crime: Do Local Institutions Matter?" Journal of Research in Crime and Delinquency 37 (1): 31-63. 
Popkin, Susan, Diane K. Levy, Laura E. Harris, Jennifer Comey, Mary K. Cunningham, and Larry Buron. 2002. "HOPE VI Panel Study: Baseline Report." Washington, DC: The Urban Institute Metropolitan Housing and Communities Policy Center.

Popkin, Susan J., Bruce Katz, Mary K. Cunningham, Karen D. Brown, Jeremy Gustafson, and Margery Austin Turner. 2004. "A Decade of HOPE VI: Research Findings and Policy Challenges." Washington, DC: Urban Institute.

Popkin, Susan J., Diane K. Levy, Laura E. Harris, Jennifer Comey, Mary K. Cunningham, and Larry F. Buron. 2004. "The HOPE VI Program: What About the Residents?" Housing Policy Debate 15 (2): 385-414.

Portes, Alejandro. 1998. "Social Capital: Its Origins and Applications in Modern Sociology," Annual Review of Sociology 24: 1-24.

Portes, Alejandro, and Patricia Landolt. 2000. "Social Capital: Promise and Pitfalls of Its Role in Development," Journal of Latin American Studies 32: 529-547.

Putnam, Robert D. 2007. "E Pluribus Unum: Diversity and Community in the Twenty-First Century (the 2006 Johan Skytte Prize Lecture)," Nordic Political Science Association 30 (2): 137-174.

_. 2000. "Bowling Alone." New York: Simon \& Schuster.

Saegert, Susan, and Gary Winkel. 2004. "Crime, Social Capital, and Community Participation," American Journal of Community Psychology 34 (3-4): 219-33.

1998. "Social Capital and the Revitalization of New York City's Distressed Inner-City Housing," Housing Policy Debate 9 (1): 17-60.

Sampson, Robert J. 2009. "Disparity and Diversity in the Contemporary City: Social (Dis)Order Revisited," The British Journal of Sociology 60 (1): 1-31.

Sampson, Robert J., and Stephen W. Raudenbush. 1999. "Systematic Social Observation of Public Spaces: A New Look at Disorder in Urban Neighborhoods," American Journal of Sociology 105 (3): 603-651.

Sampson, Robert J., Stephen W. Raudenbush, and Felton Earls. 1997. "Neighborhoods and Violent Crime: A Multilevel Study of Collective Efficacy," Science 277 (5328): 918-924.

Sánchez-Jankowski, Martin. 2008. Cracks in the Pavement: Social Change and Resilience in Poor Neighborhoods. Berkeley, CA: University of California Press.

Skogan, Wesley G. 1990. Disorder and Decline: Crime and Spiral of Decay in American Neighborhoods. Berkeley, CA: University of California Press.

Small, Mario L. 2006. "Neighborhood Institutions as Resource Brokers: Childcare Centers, Interorganizational Ties, and Resource Access Among the Poor," Social Problems 53 (2): 274-292.

Small, Mario L., Erin M. Jacobs, and Rebekah Peeples Massengill. 2008. "Why Organizational Ties Matter for Neighborhood Effects: Resource Access through Childcare Centers," Social Forces 87 (1): 387-414. 
Small, Mario L., and Monica McDermott. 2006. "The Presence of Organizational Resources in Poor Urban Neighborhoods: An Analysis of Average and Contextual Effects," Social Forces 84 (3): 1697-1724.

Smith, Neil. 1996. The New Urban Frontier. New York: Routledge.

Smith, Robin. 2002. Housing Choice for HOPE VI Relocatees. Washington, DC: Urban Institute.

Smith, Sandra Susan. 2007. Lone Pursuit: Distrust and Defensive Individualism Among the Black Poor. New York: Russell Sage Foundation.

- 2005. "Don't Put My Name on It: Social Capital Activation and Job-Finding Assistance among the Black Urban Poor," American Journal of Sociology 111 (1): 1-57.

—. 1995. "Poverty Concentration and Social Networks: Implications for Joblessness." Paper presented at the Annual Meetings of the American Sociological Association, Washington, DC, August.

Sztompka, Piotr. 1999. Trust: A Sociological Theory. Cambridge, United Kingdom: Cambridge University Press.

Tigges, Leann M., Irene Browne, and Gary P. Green. 1998. "Social Isolation of the Urban Poor: Race, Class and Neighborhood Effects on Social Resources," The Sociological Quarterly 39 (1): 53-77.

U.S. Census Bureau. 2000. "United States Census 2000 Summary File 1." Available at http://www. census.gov.

U.S. Department of Housing and Urban Development (HUD). 2008a. "About HOPE VI." Washington, DC: U.S. Department of Housing and Urban Development. Available at http://www.hud.gov/ offices/pih/programs/ph/hope6/about/.

. 2008b. "Housing Choice Vouchers Fact Sheet." Washington, DC: Department of Housing and Urban Development. Available at http://www.hud.gov/offices/pih/programs/hcv/about/ fact_sheet.cfm.

Vale, Larry J. 2002. Reclaiming Public Housing. Cambridge, MA: Harvard University Press.

van Beckhoven, Ellen, and Ronald van Kempen. 2003. "Social Effects of Urban Restructuring: A Case Study in Amsterdam and Utrecht, The Netherlands," Housing Studies 18 (6): 853-875.

Van Bergeijk, Erik, Gideon Bolt, and Ronald van Kempen. 2008. "Social Cohesion in Deprived Neighborhoods in The Netherlands: The Effect of the Use of Neighborhood Facilities." Paper presented at the Annual Meeting of the Housing Studies Association, York, United Kingdom, April 2-5, 2008.

Wacquant, Loic, and William Julius Wilson. 1989. "The Costs of Racial and Class Exclusion in the Inner City," Annals of the Academy of Political and Social Science Volume 501, Number 1: 8-25.

Wellman, Barry. 2001. "Physical Place Versus Cyberplace: The Rise of Personalized Networking," International Journal of Urban and Regional Research 25 (2): 227-252. 
1996. "Are Personal Communities Local? A Dumptarian Reconsideration," Social Networks (18): 347-354.

Whyte, William H. 1988. City: Rediscovering the Center. New York: Anchor.

Wilson, William Julius. 1996. When Work Disappears: The World of the New Urban Poor. New York: Random House.

- 1987. The Truly Disadvantaged. Chicago: The University of Chicago Press. 
